\section{Mal-estar docente na escolarização: reflexões a partir do relatório escolar.}

\author{
Cristiana Carneiro \\ Rafaela Amaral Cunha do Nascimento
}

\begin{abstract}
RESUMO
Compreendendo o mal-estar como consequência dos conflitos inevitáveis entre o individual e o coletivo (Freud, 1930/1995), o presente trabalho tem como proposta contribuir para a investigação do mal-estar e sua expressão em professores. Partindo do entendimento que a expressão do mal-estar se constitui em um crivo de compreensão para o descontentamento frente às exigências da cultura sobre o sujeito, pergunta-se como o mal-estar se apresenta referido à relação professor-aluno. 0 estudo surgiu a partir da experiência de um grupo de pesquisa feito em parceria entre as faculdades de Educação da UFRJ e da UFF e também o Instituto de Psiquiatria da UFRJ com o SPIA, Serviço de Psiquiatria da Infância e Adolescência, que objetivou questionar como o mal-estar é vivenciado pelos diversos agentes envolvidos no processo educacional. Neste trabalho, especificamente, através de uma análise documental da escrita do relatório escolar, temos como objeto o discurso de educadores através de 12 relatórios escolares encaminhados aos pais e/ou à saúde mental. 0 estudo compreende que o mal-estar como ferramenta teórico-conceitual para pensar o relatório, contribui para uma reflexão sobre possíveis atravessamentos subjetivos no cotidiano de educadores e alunos.
\end{abstract}

Palavras-chave: relatório escolar; mal-estar; psicanálise; educação;

\section{ABSTRACT}

\section{Teacher malaise in schooling: Reflections from the school report}

Understanding malaise as a consequence of the inevitable conflicts between the individual and the collective (Freud, 1930/1995), the present work aims to contribute to the investigation of malaise and its expression in teachers. Based on the understanding that the expression of malaise reveals a discontent in face of the demands of culture on the subject, one wonders how the malaise is presented in relation to the teacher-student relationship. The study arose from the experience of a research group carried out in partnership between the faculties of UFRJ and UFF and also UFRJ with SPIA, which aimed to question how malaise is experienced by the various agents involved in the educational process. In this work, specifically, through a documentary analysis of the writing of the school report, we have as object the speech of educators through 12 school reports sent to parents and / or mental health. The study understands that malaise, as a theoretical-conceptual tool for thinking about the report, contributes to a reflection on possible subjective crossings in the daily lives of educators and students.

Keywords: school reports; malaise; psychoanalysis; education;

\section{Sobre os Autores}

\section{C.}

http://orcid.org/0000-0002-4042-

1155

Universidade Federal do Rio de Janeiro, Rio de Janeiro - RJ cristianacarneiro13@gmail.com

R. A. C. N.

http://orcid.org/0000-0002-7677$610 \mathrm{X}$

Universidade Federal do Rio de Janeiro, Rio de Janeiro - RJ nascmnto.r@gmail.com

\section{Direitos Autorais}

Este é um artigo aberto e pode ser reproduzido livremente, distribuído, transmitido ou modificado, por qualquer pessoa desde que usado sem fins comerciais. 0 trabalho é disponibilizado sob a licença Creative Commons CC-BY-NC

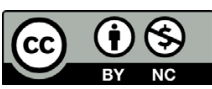




\section{H'INTERACÃO EM PSICOLOGIA}

Como uma possibilidade de satisfação substitutiva à energia investida pelo indivíduo nos desejos que encontraram interdição do mundo externo, Freud (1930/1995) menciona a sublimação, um mecanismo de defesa que redireciona a energia pulsional, dirigindo-a para outras metas e atos aceitos e valorizados pela sociedade. Para o autor, a sublimação seria então uma saída, uma forma de administração do mal-estar. A religião, a arte, a ciência e o trabalho podem ser alvos de redirecionamentos pulsionais que correspondam à natureza do aparelho psíquico em sua busca por prazer. Em relação ao trabalho, Freud (1930/1995) o define como uma das principais conexões do indivíduo com a cultura, fornecendo aos sujeitos um lugar em comunidade.

De outro modo, no artigo Análise Terminável e Interminável, de 1937, Freud caracterizou os ofícios de governar, educar e psicanalisar como impossíveis. Um dos argumentos defendidos por ele seria de que estes trabalhos sempre apresentarão resultados insuficientes. Esta impossibilidade estaria relacionada justamente ao fracasso que necessariamente os homens terão para modelar e formar os sujeitos segundo seus ideais, ou a um ideal cultural mais estanque, visto que não há, segundo Freud (1937/1988), possibilidade de domar o pulsional por inteiro. Há algo que sempre resiste a uma análise, educação ou um governo, absolutos. Nesta ótica, acreditar num êxito educativo absoluto seria não levar em conta a tensão permanente do processo civilizatório e do indomável como constituinte do humano.

Os profissionais da educação seriam responsáveis pela tarefa de transmitir as noções necessárias para compreender os valores, a moral e a lógica das relações sociais de sua cultura. Ao assumir a tarefa de educar uma criança, o educador terá de lidar com a frustração, já que terá que ajustar seu ideal diante do aluno real. $\mathrm{A}$ escola, como ferramenta de mediação cultural, acolhe para si uma problemática que não pode ser solucionada de forma definitiva, mas para a qual é convocada insistentemente a apresentar respostas, que serão sempre provisórias e incompletas, mas fundamentais à manutenção da cultura. Além dessas complexidades do ofício de educar, o educador hoje se depara com uma sala heterogênea de divergentes desejos, apelos, interesses e necessidades do grupo, que geralmente não correspondem a modelos ideais de turma. Para Pereira e Blum (2014), o desencontro entre o esperado e o que existe acarreta, muitas vezes, desapontamento quando algo que era objetivado não ocorre na prática profissional, e o sentimento de impotência pode dificultar a possibilidade de trabalhar com as diferenças.
Por intermédio da literatura supracitada, podemos entender que o mal-estar não se encontra em um evento isolado que irrompe na escola, mas sim como algo constituinte das relações humanas. Especialmente na escola, diante do mal-estar e impotência, os docentes deparam-se com ideais educativos inalcançáveis e com uma cena pedagógica imprevisível. Para Zibetti (2004), o professorado sente que a expectativa atribuída a ele, seja pela instituição ou pela sociedade em geral, é de que será aquele que tem tudo o que o outro (o aluno) precisa, que responderá sempre à altura ao papel que lhe foi atribuído. Vistas as diferentes formas em que o mal estar encontra-se presente nas relações, principalmente dentro da instituição escolar, nossa pesquisa se utilizou desse referencial teórico para realizar um mapeamento de como a temática se manifesta no discurso dos professores frente ao processo de escolarização. Buscando identificar como o mal-estar pode ser visto dentro do contexto dos dispositivos escolares enquanto prática e discurso, no presente trabalho iremos utilizar de um tipo específico de material - o relatório escolar - como objeto para investigar e analisar as marcas discursivas de mal-estar, para daí tentar compreender como a escola se apropria e discursa a partir dessa produção textual. Partindo do entendimento que o mal-estar se articula a um descontentamento frente às exigências da cultura sobre o sujeito, pergunta-se como o mal-estar pode ser uma chave de leitura para a relação professor-aluno expressa nesses relatórios. A hipótese inicial era a de que os relatórios poderiam também trazer rastros da marca conflitiva entre o individual e o coletivo. Tal empreitada se justifica sobretudo para aprofundar uma reflexão sobre os descontentamentos vivenciados no cotidiano escolar. A partir disso, as questões primordiais que atravessaram a discussão do grupo de pesquisa e extensão que conduziram este trabalho são: Quais os principais pontos referidos nestes relatórios? Os relatórios são documentos avaliativos? Se sim, o que eles estão avaliando? 0 que eles pretendem observar, descrever e relatar? Como pretendem? Para quem pretendem?

\section{REVISÃO DA LITERATURA}

Ao realizar uma revisão da literatura, foi possível perceber, nos campos psicanalítico e pedagógico, a existência de um volume significativo de trabalhos que apontam e dissertam sobre um constante mal-estar docente presente na função de educar e na sua relação com o público discente (Aguiar \& Almeida, 2006, 2008; Bizarro \& Braga, 2014; Cortez et al. 2017; Diniz, 1998; Ferreira \& Pereira, 2012; Freitas \& Facas, 2013; Pizzio \& Klein, 2015; Sanches 


\section{H'INTERACÃO EM PSICOLOGIA}

\& Gama 2016; Silva, 2012; Vieira, 2014; Vieira et al., 2016; Zibetti, 2004).

Os trabalhos mencionados proporcionam um entendimento mais amplo do mal-estar do professor na contemporaneidade, demonstrando e discutindo os fatores que ocasionam sofrimento psíquico nestes profissionais. Apontam que uma parcela expressiva dos docentes hoje vivencia o exercício do magistério como um lugar de sofrimento (Aguiar \& Almeida, 2006), seja por consequência dos aspectos da realidade social em que estão inseridos (Ferreira \& Pereira, 2012), ou pelas más condições de trabalho e salário que, muitas vezes, levam o professor a realizar duplas jornadas de trabalho e, então, ocasionam grande desgaste físico (Diniz, 1998).

As causas destacadas dentro das queixas dos professores ouvidos pelos pesquisadores foram diversas. Autores como Ferreira e Pereira (2012) e Cortez et al. (2017) nos apresentam parte destas, como por exemplo: falta de recurso oferecido pela escola, que utiliza espaço físico precário e com falta de ferramentas de trabalho; elevado número de alunos por turma, que dificulta o manejo diante da demanda em lidar com tantos alunos e questões diferentes; falta de interesse: discente, dos pais em relação à educação dos filhos, da própria sociedade com o descaso de políticas públicas em relação ao ensino, e também da instituição em que estão inseridos, onde, muitas vezes, não sentem apoio dos coordenadores e diretores das escolas, vendo-se sozinhos e despreparados no momento de tomar decisões referentes às dificuldades de seus alunos. Todas essas queixas convergem para a ideia de professores desestimulados, prejudicando na formação de um vínculo com a sua profissão, o que pode resultar em frustração, baixa autoestima e mal-estar docente (Vieira et al., 2016).

Mas o que se pode compreender como mal-estar docente? Esteve (1999) afirma que a expressão é empregada para descrever "os efeitos permanentes, de caráter negativo, que afetam a personalidade do professor, resultantes das condições psicológicas e sociais em que exercem a docência, devido à mudança social acelerada" ( $p$. 98). Assim, podemos entender o mal-estar docente como uma vivência de sofrimento que mescla a vida profissional com a história pessoal desses sujeitos (Aguiar \& Almeida, 2008). E também, como vemos nas pesquisas de Siqueira e Ferreira (2003) e Pizzio e Klein (2015), um mal-estar docente que se apresenta como sofrimento físico, como dores generalizadas, perda auditiva e problemas nas cordas vocais, depressão, estresse e síndrome do pânico, o que demonstraria o crescimento dos pedidos de afastamento e licença desses profissionais.
Cristiana Carneiro e Rafaela Amaral Cunha do Nascimento

Em outras palavras, o mal-estar dos professores apresenta os efeitos negativos que se manifestam em diversos graus e formas no educador, como resultado das condições de trabalho onde está inserido, Ihe trazendo a concepção de que algo não está bem, mas sem que este saiba como modificar as causas e as consequências (Freitas \& Facas, 2013). A profissão docente padece hoje dos excessos de cobranças, metas e sistematizações excessivas que não só pressionam por bons resultados mesmo diante de sobrecarga, mas acarretam uma série de tensões ao dia a dia, dificultando o exercício e principalmente o desejo em lecionar (Vieira, 2014). A questão dos excessos de cobrança aos professores, muitas vezes, esbarra num ideário que vislumbra uma educação perfeita como possível. Tendo esse discurso como pano de fundo, muitas vezes a escola não pode ouvir, ou não oferece espaços legítimos para a discussão "dos fracassos". Como pontua Pereira (2003): "sabemos que esse profissional, mesmo se assegurando das mais excelentes técnicas e de um conjunto incontestável de competências defronta-se com o insucesso e o fracasso, seja do aluno, seja da instituição que o acolhe, seja do sistema educacional." (p. 150)

Justamente por estarmos tratando de sujeitos inseridos na cultura é que se faz impossível pensar no mal-estar docente de forma individual, desvinculado do social. Aguiar e Almeida (2008) ressalvam a importância de entender o sofrimento docente não como uma doença orgânica isolada, mas como expressão da inserção desses sujeitos na educação, e, em parte, na cultura que por meio da queixa e manifestação de seus sintomas, apontam para um desconforto subjetivo suscitado pelos costumes firmados na cultura.

Entretanto, muitas vezes esse aspecto é pouco acoIhido dentro das instituições escolares, onde se encontra o discurso de mal-estar individualizado. Kupfer (2001) nos alerta que a concepção de mal-estar, inseparável da civilização, nos remete à insatisfação estrutural como condição humana, o que é incompatível com os ideais de avanço e progresso da contemporaneidade, nos quais uma satisfação mais absoluta é compreendida muitas vezes como possível.

Com isso, pode-se vincular o mal-estar docente com as mudanças e exigências sociais que não caminham junto às singularidades e subjetividades dos docentes inseridos nas instituições educativas. Convivemos hoje em um contexto social onde as mudanças e demandas ocorrem de forma cada vez mais acelerada, e o sistema escolar é também cada vez mais exigido a exercer seu ensino de forma rápida e eficaz para atender às novas de- 


\section{HZ INTERACÃOEM
PSICOLOGIA}

mandas culturais. Porém, o que ocorre, segundo Sanches e Gama (2016), é que essas mudanças trazem consigo demandas que o professor nem sempre tem condições para cumprir. 0 excesso de demandas pode acarretar aumento de estresse e sofrimento, já que aumenta a carga de responsabilidade e tarefas do docente, ao mesmo tempo em que inutiliza, muitas vezes, práticas e saberes que faziam parte do seu cotidiano.

Podemos ver, portanto, como nos apresenta Bizarro \& Braga (2014), que as mudanças contemporâneas no sistema educacional afetam a forma como o papel do professor é concebido e, também, as exigências de competência destes profissionais. Esses fatores frequentemente não levam em conta as vivências subjetivas dos docentes, o seu desgaste físico e emocional, e toda a pressão por eficácia, variáveis acumuladas em sua formação. Zibetti (2004) localiza, desde o início da carreira profissional, o sentimento de angústia do professor não só pela inexperiência, mas pela expectativa do desejo do outro: o aluno, que é imprevisível. 0 contexto social também configura o imaginário dos professores, quando acreditam que precisam atender a uma exigência da instituição e dos pais, na tarefa de garantir a aprendizagem de todo seu corpo discente com excelência. Nesse contexto de mudanças, cabe ainda ressaltar as mudanças acentuadas no exercício da autoridade. Impactando diretamente na relação professor-aluno, a construção da autoridade passa a ser mais laboriosa e menos garantida pelo entorno social (Lebrun, 2010). Para Lebrun (2010) não estaríamos vivendo uma crise da autoridade, mas uma crise de legitimidade, onde certos papéis sociais, antes socialmente reconhecidos como legítimos em seu exercício de autoridade, hoje não encontram a mesma adesão em grupo amplo, precisando trabalhosa e individualmente construir seu espaço de reconhecimento. Consequência disso seria o sentimento de desamparo e ameaça de fracasso, perdendo o respeito e o reconhecimento como profissional. É nesse cenário que Zibetti (2004) localiza a angústia como decorrente de uma tarefa de supor o que falta ao outro diretamente relacionada à expectativa de atender à exigência do contexto institucional em que está inserido.

Como pudemos ler nessa breve revisão de literatura, muitas leituras de autores pós-freudianos se dedicam ao estudo do mal-estar, sendo uma parte desses dedicada especificamente a pensá-lo na escola. A polissemia do texto freudiano, bem como o fato do mal-estar não ser um conceito metapsicológico propriamente dito, concorrem para uma ampla interpretação do termo. Nesse sentido, os autores do texto partilham das leituras que o compreendem como parte de um conflito insuperável entre o individual e o coletivo.

\section{METODOLOGIA}

Com a perspectiva de análise que o mal-estar não se encontra em um evento isolado que irrompe na escola, mas sim como algo constituinte das relações humanas, o projeto "Infância, adolescência e mal-estar na escolarização: estudo de casos em psicanálise e educação" realizou um estudo de casos de crianças e adolescentes direcionadas ao setor de psiquiatria (SPIA) do IPUB com queixas ligadas à escolarização. A partir deste mapeamento, o grupo teve a oportunidade de analisar os problemas na escolarização a partir de uma construção de material ampla onde diferentes olhares e discursos foram enunciados e articulados, reconhecendo a importância analítica de considerar múltiplas variáveis na produção do mal-estar. Assim, partimos do crivo de que o mal-estar é uma produção resultante do contexto escolar, sendo a partir dessa ótica que trabalhamos a elaboração da pesquisa. Embora as duas autoras do texto sejam psicanalistas, cumpre ressaltar que, nessa pesquisa, a psicanálise foi uma perspectiva teórica de fundo, um olhar, naquilo que podemos chamar de psicanálise estendida, psicanálise fora dos muros. Isso significa que não se trata de uma pesquisa psicanalítica stricto sensu, como a pesquisa clínica do inconsciente. Parte-se da premissa do inconsciente, no entanto este não é o objeto da pesquisa.

Para dar cabo ao objetivo da pesquisa, a equipe adotou diferentes formas e técnicas de acompanhamento escolar dessas crianças e adolescentes de acordo com suas singularidades e da disponibilidade das escolas. A pesquisa em questão teve a autorização do Comitê de Ética (parecer no 789.946) e da $2^{\mathrm{a}}$ CREs (Coordenadoria Regional de Educação), o que nos possibilitou a entrada nas escolas.. Com isso, foi possível a construção de um material extenso do campo interventivo dos vários discursos, mais especificamente a família, a escola, especialistas e a própria criança/adolescente.

No eixo do discurso da escola, a equipe deparou-se com os relatórios escolares, uma documentação na qual se encontra presente a enunciação dos professores sobre os alunos. Esse material demonstrou sua relevância ao elucidar as informações sobre o funcionamento do sistema disciplinar das escolas envolvidas e os tipos de estratégias e perspectivas, das preventivas às punitivas, que foram utilizadas com as crianças e adolescentes. 
Os relatórios divergem de diversas formas. Alguns se apresentam em forma narrativa, descrevendo uma avaliação de um discente em sala, já outros foram preenchidos com o mesmo intuito, porém na forma de escalas e/ou questionários. 0 interessante a ser destacado aqui é que, mesmo apresentando técnicas singulares, todos esses relatórios reproduzem o padrão do uso da escrita para descrever as ações e o comportamento discente a outros agentes (como os responsáveis, ou um especialista), se utilizando deste escrito não só para avaliar, mas demonstrar também possíveis rastros do mal-estar presente dentro do processo educativo.

\section{SOBRE A PESQUISA}

O eixo Escola, em particular e sobre o qual nos ateremos, teve seus dados produzidos durante os anos de 2013 e 2014 a partir de observações participantes nas escolas, entrevistas com os educadores, grupos com professores e relatórios escolares que foram anexados aos prontuários das crianças e adolescentes participantes da pesquisa. Ao total foram produzidos relatórios de 69 visitas às escolas e 22 reuniões com equipes pedagógicas redigidos pelas bolsistas, relatando seus encontros nas seis escolas (duas escolas particulares, três escolas municipais e uma creche-escola que funciona como uma instituição de grupo comunitário, mantida através de doações empresariais), frequentadas por cinco participantes da pesquisa, sendo duas escolas municipais habitadas pelo mesmo participante, todas dentro da cidade do Rio de Janeiro.

Anexados à ficha de encaminhamento das crianças e adolescentes participantes do estudo de casos, encontramos 12 relatórios redigidos pela escola, sendo $9 \mathrm{em}$ forma dissertativa e uma na forma de questionário avaliativo-descritivo sobre desempenho discente em sala de aula com respostas preestabelecidas. Os outros dois relatórios divergem dos demais: um como solicitação escolar de 'uma avaliação psicológica' ao 'responsável do aluno' (grifo a partir do relatório); e outro uma escala de pontuação para pais e professores (MTA-SNAP-IV) que foi preenchida por uma professora de um dos casos, a pedido do especialista da saúde que o acompanhava.

Observamos, então, que cada instituição priorizou um modelo de relatório que acreditava ser mais pertinente, não havendo uniformidade entre eles. A partir desta observação fez-se relevante pesquisa bibliográfica, na tentativa de descobrir o que é destacado na produção acadêmica de diferentes campos de conhecimento acerca do tema, para melhor compreensão e análise do discurso escrito nos relatórios.

A pesquisa limitou-se aos catálogos online de artigos, teses e dissertações presentes no banco de dados dos anais de eventos colóquios do LEPSI (IP/FEUSP) de 1999 a 2014, aos trabalhos presentes na plataforma da CAPES, do SciELO, PePSIC, Google Acadêmico e da própria UFRJ, em sua plataforma eletrônica de pesquisa Minerva. 0 levantamento deu-se com a busca de seis expressões possíveis de serem associadas ao objeto de estudo: laudo escolar, notificação escolar, documento escolar, advertência escolar, relatório escolar e ocorrência escolar. As três primeiras expressões apresentaram apenas resultados pouco relacionados com o presente objeto de estudo, trazendo uma discussão relacionada com campos médicos, jurídicos ou políticos administrativos da Secretaria de Estado da Educação que não se relacionam diretamente com a discussão proposta. As demais expressões levaram a parte da literatura utilizada para a metodologia de pesquisa. Já a busca com os termos: diário de campo professores e escrita docente apresentou pesquisas que se utilizam do processo de registro escrito de professores (ou estudantes na formação em licenciatura) com intuito de provocar uma reflexão sobre a prática de ensino.

Algumas resoluções publicadas pela SME (Secretaria Municipal de Educação) do Rio de Janeiro dissertam sobre registros de avaliação e as normas a serem seguidas pelo docente para sua execução. Como esclarece Gama (2006), com as regras e mudanças nas direções estabelecidas nas escolas municipais do Rio de Janeiro, e com a introdução da Resolução SME n $684 / 2000$, os professores foram obrigados a redigir relatórios individuais e relatórios de sínteses das turmas como forma de registros da avaliação. Nestes, deveriam ser apresentados indicadores de autonomia e aprendizagem. Pela Resolução SME $n^{\circ} 776 / 2003$, a utilização do relatório como processo avaliativo foi excluída, sendo somente realizada em regime de exceção a necessidade de formulação de relatórios de turma ao conselho de classe, e os relatórios individuais somente em caso de transferência de estudantes dentro do primeiro Ciclo de Formação (Gama, 2006).

As mudanças prosseguiram com a Resolução SME no $1123 / 2011$ (vigente até o presente momento), onde as normativas manifestas dissertam sobre os relatórios, compreendendo-os como documentos da Avaliação Escolar também apenas em situações singulares, tais como nos casos de transferência discente no ensino fundamental e no PEJA (Programa de Educação de Jovens e Adultos). No direcionamento para sua escrita, consta somente a premissa de que "conterá observações sobre 


\section{HT INTERACÃO EM
PSICOLOGIA}

o desenvolvimento e a aprendizagem, elaboradas a partir das anotações no Diário de Classe" (p. 14), e ser anexado junto ao Histórico Escolar. Outra utilização como instrumento de avaliação é na forma de relatório de acompanhamento, para estudantes de Classe Especial; que deve ser enviado aos responsáveis, após cada Conselho de Classe.

Exceto nos casos citados acima, a Resolução SME n 1123/2011 mantém como obrigatória a elaboração de relatório individual sobre um(a) discente somente quando este obtiver num bimestre letivo conceito global I (Insuficiente), "anotando-se suas dificuldades e as estratégias previstas para sua recuperação” (p.13). Também após o $5^{\circ}$ - e último - COC (Conselho de Classe), caso haja um discente ou mais em reprovação, cada docente deve elaborar um relatório individual sobre este, "explicitando os motivos que levaram à sua conceituação como Insuficiente (I)" (p.13).

Como levantado por Gama (2006), a Resolução vigente da Secretaria Municipal de Educação institui normas com o intuito de monitorar e controlar o desempenho estudantil, a prática docente e a gestão das unidades escolares, transformando os processos de avaliação, e com isso os relatórios, em instrumentos de verificação. No mais, os relatórios só podem avaliar os conhecimentos constituídos pelos discentes num determinado momento único de sua trajetória escolar, sem enxergar a aprendizagem ou a prática pedagógica como um processo contínuo e essencial para o desenvolvimento de seus estudantes.

\section{SELEÇÃO DE CATEGORIAS}

Como mencionado anteriormente, o mapeamento realizado pelo grupo de pesquisa encontrou diferentes materiais, sendo um destes o relatório escolar. Após leituras conjuntas deste material, o grupo de pesquisa reconheceu algumas possíveis marcas do mal-estar enunciado por educadores através dos relatórios. Conseguimos identificar uma série ampla de cobranças, reclamações, elogios e avaliações nos relatórios que demonstraram, pela perspectiva docente, as dificuldades vividas no ato de educar e as tensões vividas na relação entre professores e alunos. Entendendo que a subjetividade do educador que produz o relatório não deve ser excluída, utilizamos o mal-estar como crivo de análise para leitura nestes documentos, seja de forma direta ou indireta, guiados através das questões primordiais que atravessaram a pesquisa. Acreditamos que realizar uma análise dos relatórios poderia trazer um olhar particularizado para o discurso es- crito nesse material selecionado.

Os relatórios apresentaram 12 temáticas centrais que foram estabelecidas através do número de vezes que apareciam no texto, sendo excluídas aquelas que só apareceram em um relatório. Por não haver uma padronização nos relatórios, hipotetizamos que tanto sua forma pode revelar tendências da instituição específica, quanto da subjetividade do professor, já que de certa forma foi ele que escolheu como e o que relatar. Num segundo momento, foram criadas subcategorias denominadas a partir de dicotomias e pares de opostos presentes no discurso redigido pelos docentes. Foram formuladas como: $1^{\circ}$ - agitação ou movimento; $2^{\circ}$ - atenção ou concentração versus dispersão; $3^{\circ}$ - capacidade de realizar tarefas; $4^{\circ}$ - capacidade de espera versus ansiedade; $5^{\circ}$-interesse versus desinteresse; $6^{\circ}$ - relacionamento com o grupo; $7^{\circ}$ - relacionamento com professor; $8^{\circ}$ - disciplina ou indisciplina; $9^{\circ}$ - organização; $10^{\circ}$ - características subjetivas e $11^{\circ}$ - aprendizagem e desempenho.

Apesar dos relatórios apresentarem temáticas diversas, optamos, no presente trabalho, por eleger a de maior recorrência, compreendendo que esta insistência pode nos trazer informação importante. Esse recorte torna exequível a delimitação do artigo, no entanto não esgota a discussão mais ampla. Ressaltamos, ainda, que a pesquisa não teve como objetivo uma "amostragem" extensa do campo e que, portanto, apresenta certos limites, o que não invalida seu aprofundamento qualitativo e sua análise micropolítica. A mais recorrentemente articulada ao mal-estar disse respeito às expectativas dos professores não correspondidas quanto ao desempenho de seus alunos. A partir disso, nosso interesse voltou-se para mapear como essas expectativas eram manifestas dentro das temáticas e se era possível compreender o mal-estar docente a partir dessa chave de compreensão.

\section{PANORAMA DOS RELATÓRIOS E ANÁLISE}

A busca e análise dos trabalhos proporcionaram algumas observações interessantes. Um primeiro ponto observado na procura é que, apesar de não haver nenhuma legislação específica ou regimento que paute este tipo de documentação escolar, os primeiros resultados de busca referentes ao termo "modelo relatório escolar" no Google apresentam aproximadamente 632.000 resultados, com imagens e formulários guiando o professor a realizar relatórios sobre o perfil de seu aluno e de sua aluna. Esse dado demonstra que apesar de não existir um preceito que regulamente a prática desse instrumento, já 


\section{H. INTERACÃO EM ET. PSICOLOGIA}

é amplamente difundido o seu uso pelos profissionais da educação. Tanto que muitos sites voltados para área da educação e até blogs docentes realizam publicações sugerindo dicas e referências para a elaboração de um relatório de desempenho escolar. Outro ponto relevante, que também foi percebido nos documentos selecionados e analisados, é que o foco, tanto nos discursos dos agentes escolares que redigiram os relatórios, quanto nos dos pesquisadores consultados na revisão bibliográfica, pontuaram e registraram mais pontos de tensão e falhas da cena escolar, do que aspectos mais positivos e/ou subjetivos.

Com os resultados obtidos a partir dos termos restantes da busca, realizou-se primeira seleção, optando por trabalhos que realizaram uma análise ou discussão do discurso escolar a partir da ótica do professor. Foram selecionadas nesta fase as publicações mais relacionadas ao debate proposto, predominando entre elas uma discussão sobre o mal-estar do professor e a dificuldade no exercício de seu ofício. Os autores compreendem o mal-estar docente como "uma marca da escola contemporânea", já que "a sociedade espera da escola bem mais do que esta pode, de fato, oferecer; e isso, sem dúvida, mobiliza afetos de ansiedade no professor que, via de regra, não consegue dar conta." (Silva, 2012. p. 9). No revés de realizar um olhar singularizado para o aluno, o professorado compreende a dificuldade de aprendizagem como algo fora de seu encargo, sem visualizar a rede de fatores que influenciam na problemática (como fatores socioeconômicos, por exemplo), preferindo recorrer a outras instâncias para lidar com o incômodo, o que gera um crescente número de encaminhamentos a especialistas (Carneiro et al., 2016).

Em sua investigação sobre produção textual dos agentes educacionais, Aquino (2005) tomou como objeto de análise todos os encaminhamentos de estudantes à coordenação escolar das seis salas de ensino médio de uma escola pública de São Paulo durante um ano letivo. 0 autor concluiu que o uso desses encaminhamentos era utilizado para manter um modelo de ordem disciplinar hierárquica, onde discentes deveriam obedecer às regras ditadas pelo corpo docente, sem abertura de contestação. Quando o discente transgredia a ordem imposta, o encaminhamento era realizado através de uma 'ocorrência disciplinar' em forma de um relatório redigido e armazenado pelo coordenador que descreve e pune a ação desviante. Tendo em vista a observação dessa dinâmica, Aquino (2011) pontua em uma de suas considerações que o regimento adotado pelo cotidiano escolar atua buscando uma forma de normatização, ou seja, exercendo estratégias múltiplas de controle da conduta discente por meio da padronização não apenas dos gestos, mas sobretudo de suas próprias individualidades. Assim, a escola acaba por se distanciar do mundo juvenil, aumentando a dificuldade de comunicação entre os dois, gerando um enfraquecimento de sua capacidade educativa.

Ratto (2007) realiza uma tese a partir dos livros de ocorrências do primeiro ao quarto ano do Ensino Fundamental de uma escola pública de Curitiba. A autora defende que essa documentação escolar se constitui em uma narrativa com o intuito de identificar e corrigir as ditas irregularidades dos alunos, legitimando uma ação de vigilância e modelação de identidades. Entretanto, é importante ressaltar que a educação necessariamente implicará em mecanismos de regulação. Seja como condição estruturante da subjetividade, seja como continuação da restrição pulsional que condiciona a civilização, em "todo ato educativo há embutido uma cota de dever ser" (Lajonquière, 1997, p. 31). Isto quer dizer que toda educação, no bom sentido do termo, se efetuará numa tensão entre liberdade e regulação.

$\mathrm{Na}$ leitura dos relatórios, surgiu o questionamento a respeito de existirem ou não diferenças entre os redigidos pelas escolas públicas e as escolas particulares. A primeira distinção a ser feita é a observação de que os relatórios redigidos pelas escolas públicas municipais seguiam a mesma resolução normativa da Secretaria de Educação (SME-RJ), que apesar de não explicitar um modelo fixo de relatório a ser redigido, exige que seus docentes apresentem os relatórios nas ocasiões já explicitadas. No caso das escolas particulares, resta dúvida sobre se há e, havendo, qual tipo de normativa era disponibilizada ao professorado. Cabe ressaltar que, em referência aos 12 relatórios analisados nesta pesquisa, anexados aos prontuários de cada criança/adolescente do estudo de casos, a maioria foi redigida pelas escolas particulares. Nestes, seu parecer sobre a aprendizagem e as dificuldades discentes em questão eram, predominantemente, dirigidos para outros agentes envolvidos na educação (fossem pais, mães, demais responsáveis ou especialistas da saúde). De outra forma, como evidenciam as resoluções da SME-RJ, os relatórios das escolas públicas analisadas demonstraram direcionar o discurso para agentes internos à escola, seguindo o procedimento estabelecido.

A partir deste mapeamento, podemos compreender que o discurso docente direciona a escrita dos relatórios em uma descrição de aspectos comportamentais do aluno, mais especificamente para os aspectos que não correspondem a uma avaliação positiva. Os relatórios apresentam com frequência enunciados de característi- 


\section{HZT INTERACÃOEM
PSICOLOGIA}

cas e impossibilidades do aluno, descrevendo em quais aspectos o aluno tem dificuldade, porém sem apresentar qualquer tipo de reflexão ou aprofundamento sobre possíveis causas destes comportamentos. É possível estabelecer uma relação da dificuldade do professorado em direcionar um olhar que busque aspectos singulares do aluno, quando percebemos a frequência díspar e inferior no número de menções a características subjetivas do aluno. Isso porque a baixa frequência de menção às características subjetivas do aluno em sua articulação à relação professor-aluno-instituição pode indicar uma certa dificuldade do professor para enxergar o contexto mais amplo, para além de um ideal esperado de comportamento do aluno. Em um dos casos de estudo, é possível observar até a menção repetitiva de um tipo de comportamento fora da normativa e a completa ausência de qualquer característica subjetiva que identifique aquele aluno como sujeito, o que pode demonstrar um olhar mais universalizado, menos voltado para um aluno singular, passível de seus próprios desejos e expectativas.

1 - "A aluna apresenta um comportamento bastante agitado..." [Orientadora Educacional; A Direção da Escola XXX - Relatório da aluna XXX].

2 - "A aluna durante a aula apresenta um comportamento agitado e dispersivo." [Orientadora Educacional; Relatório sobre a aluna XXX].

3 - "A aluna apresenta um comportamento agitado..." [Orientadora Educacional; Relatório da aluna XXX].

4 - "A aluna, R, é muito agitada durante as aulas..." [Orientadora Educacional; Relatório da aluna XXX].

Sua escrita é estritamente descritiva, pontuando seja a atenção, agitação ou outras características comportamentais como uma reação inapropriada, que não vai de acordo com o esperado e não como comportamento passível de envolvimento e intervenção pedagógica. Ou seja, o relatório não presentifica a ação dos educadores diante destes comportamentos "inapropriados", como lidaram ou o que entendem a partir disto. Também não traz nuances relativas ao contexto das ações agitadas. Assim, a escrita evidenciada nos relatórios não sugere uma construção de pensamento do professor a respeito das consequências e efeitos de suas ações sobre a agitação e atenção da aluna, descrevendo estes mais pela perspectiva do seu incômodo. Hipotetizamos aqui que, ou isto é omitido no relatório (apesar de na prática ocorrer algum outro tipo de envolvimento), ou de fato a escola - e o educador como seu representante -individualizam o comportamento do aluno, patologizando-o. Neste caso, o comportamento não estaria relacionado ao ambiente escolar, sua estrutura e postura dos educadores, mas seria um "transtorno" específico daquela aluna.

5 - "Quando em aula, algumas vezes, verbaliza algo que não faz parte do contexto da mesma e acha graça ao fazê-lo." [Orientadora Educacional; Relatório da aluna $\mathrm{XXX}$.

Esse trecho parece expressar um certo ideal de que a aluna só poderia verbalizar aquilo que seja pertinente ao contexto da aula, excluindo a possibilidade de que sua estratégia para rir, ou talvez chamar a atenção, também possa ser pertinente ao contexto educativo. Correa (2010), que também realizou uma discussão pelo viés psicanalítico no campo da educação, defende que o professor é guiado por um eixo imaginário em torno do qual se estrutura a busca por uma total eficiência da tarefa instituída de dirigir o desejo dos alunos para aquilo que o professor julga pertinente. Quando este se depara com ausência do interesse, o educador se sente interpelado por um enigma, já que esta falta de desejo é entendida como um desconhecimento da relevância da aprendizagem, onde o aluno não aprende porque não sabe que é importante aprender. A partir disso, decorre o pensamento, modelado pela concepção do que é o ato educativo, de que o professor necessita fazer algo que demonstre e estimule o aluno sobre a importância do conhecimento. Este conflito escolar pode desembocar na sensação de um erro, onde ou o educador não possui a técnica adequada, ou o aluno não corresponde às empreendidas do educador, resultando em uma culpabilização individualizada do aluno.

6 - “Compreende as regras de sala de aula mas não as aceita e muitas vezes desafia a professora." [Professora; aluno XXX, 07/04/2011, Avaliação do Desempenho em Sala de Aula].

Como podemos ler no trecho da avaliação acima, a autoridade do professor é colocada em xeque várias vezes. Nesse sentido, ainda que existam as regras e que a aluna demonstre as compreender, elas não são seguidas, o que se configura num "desafio à professora". Com sua autoridade "posta à prova" essa professora, provavelmente, terá que reafirmar seu lugar de autoridade ou tentar construí-lo na continuidade de seu ofício. Isso estaria de acordo com a ideia de Lebrun (2010) de que no contemporâneo o lugar de autoridade do professor não estaria tão legitimado pelo meio social. Hipotetizamos, a partir desse trecho, que a professora terá mais um trabalho diante de todas suas demandas. 0 desafio, então, poderia ser fonte de mal-estar exigindo mais energia e trabalho. De outro modo, a aluna não cumpre o esperado, fazendo com que o ideal de aluno seja também desafiado. 


\section{H'INTERACÃO EM PSICOLOGIA}

Num estudo sobre queixas escolares dirigidas à saúde mental, Carneiro e Coutinho (2015) demonstraram que a agitação e a inquietude são queixas predominantes, recorrentes e fonte de mal-estar no âmbito escolar. Uma hipótese para compreender o que fundamenta esse tipo de queixa é justamente a distância entre a imagem de um aluno ideal e a do aluno real. Por consequência, o efeito de uma meta irreal e grandiosa pode corroborar para a negação do estudante como sujeito. No trecho abaixo, o professorado situa um fato que atrapalha a dinâmica escolar, no entanto encontramos esse fato com recorrência na reclamação dos professores. Será que a escola também não é lugar de conversar? Como esse conversar, muitas vezes transbordante, pode ser incluído na escola? Podemos também pensar o quanto de mal-estar experiencia um professor ao falar diversas vezes e não ser escutado pelos alunos.

7 - "Durante este período de distração, a aluna busca conversa com os alunos ao seu redor, atrapalhando assim não só a ela, mas a outros também." [Professora e Coordenadora Pedagógica; Relatório individual XXX].

8 - "XXX tem preferência por brincadeiras que envolvam violência e utiliza de hábitos pouco higiênicos para provocar repulsa nos colegas, tais como: forçar escarro, arrotar, soltar gases etc., o que dificulta seu relacionamento com o grupo escolar." [Relatório da Professora sobre o discente XXX, 04 mai. 2012].

Nas duas falas acima, a educadora ressalta claramente a sua opinião sobre os estudantes, relacionando o comportamento com suas hipóteses (na primeira fala, a hipótese de que a aluna atrapalha outros e, na segunda, a de que o aluno tem dificuldades pois possui hábitos que não correspondem ao grupo). Aqui não se intenta questionar se a hipótese estabelecida por ela está correta ou não, mas sim de pontuar que tal visão, de alguma forma, já traz algo que vai um pouco além do descritivo sem sujeito. Por exemplo, ela hipotetiza que os hábitos pouco higiênicos possam estar interferindo na interação do estudante com o grupo e que esses hábitos visam provocar repulsa. Ainda assim, sua escrita se organiza a partir de onde os estudantes faltam ou erram, demonstrando mais uma vez um mal-estar referente ao que foi estabelecido e não cumprido a contento. Indo nesta direção, conseguimos identificar um mal-estar referido à relação professor-aluno, talvez também referido a um certo ideal de aluno. $\mathrm{Na}$ fala abaixo, por exemplo, apesar de identificar que o aprendizado dos conteúdos mínimos da aluna é 'muito bom', a professora demonstra um incômodo com o fato de que esta o realiza sem recorrer explicitamente a sua presença:
9 - "Em relação à assimilação e fixação dos conteúdos a aluna é muito boa, porém em momento algum consulta a professora" [Professora e Coordenadora Pedagógica; Colégio XXXX - Relatório Individual].

Como podemos notar, esse discurso é bastante enigmático e paradoxalmente revelador. Num primeiro momento, fica clara a correspondência da aluna aos quesitos de aprendizagem, o que indicaria que tudo vai bem. Logo a seguir a frase: "porém em momento algum consulta a professora" nos faz pensar que, subjetivamente, a professora pode estar ressentida, ou se sentindo não valorizada em seu saber, ou ainda pouco importante nessa cena educativa. Tudo levando a crer que há certo mal-estar em jogo. Dito isso, ressaltamos que, embora nem sempre explicitada no relatório, a relação professor-aluno comparece de alguma forma, seja explicitamente demonstrada como na fala acima, seja indiretamente ao descrever um aluno não ideal. Se há o imaginário de um aluno ideal, há também uma contrapartida do desempenho do professor, muitas vezes colocando em xeque o que aprenderam em suas formações e aquilo que esperavam no início da carreira ou de um ano letivo, por exemplo. Nesse sentido, não há como pensar o dia a dia dos professores sem inúmeras negociações internas e externas ante às frustrações, já que educar sempre pressuporá um ideal subjetivo e da cultura mais ampla.

A partir dos relatórios, a escrita dos educadores se refere predominantemente ao mal-estar gerado por um aluno que não responde do lugar de aluno que construímos como ideal, aceito, esperado. É importante também ressaltar que esta idealização para com o outro foi encontrada em todos os eixos de análise, refletindo em todo o processo de escolarização. Pelo viés psicanalítico, podemos compreender melhor esta consequência a partir do conceito de ideal do eu, que age como uma instância introjetada, confrontando o indivíduo ao mesmo tempo que the serve como referência, formulando suas aspirações e objetivos. Como pontua Correa (2010), é possível notar este ideal também na cena educativa, influenciando na subjetividade dos agentes educacionais. Se, por um lado, os ideais são o motor de todo o trabalho educativo, sua fixidez pode corroborar, também, para a dificuldade de compreender e reconhecer o aluno como uma outra constituição subjetiva, que não corresponde exatamente a todas projeções imaginativas.

Talvez a diferença maior entre estes relatórios seja a forma como foi relatado este mal-estar. Em sua maioria, um mal-estar mais descritivo e individualizado, como um problema que diria respeito apenas ao aluno. Neste caso, teríamos a descrição do "aluno que não se encaixa", "que 


\section{H. INTERACÃO EM ET PSICOLOGIA}

não serve à escola". A individualização e patologização do comportamento tende a uma segregação do aluno que não se adapta às categorias e medidas padronizadas (Correa, 2010). Aqui também indicamos que o uso de uma escala de pontuação para pais e professores referida exclusivamente a comportamentos dos alunos (MTA-SNAP-IV), exclui a relação professor-aluno-instituição da própria produção dos comportamentos. Num outro caso, nós teríamos um relato que, também, aponta "os erros" mas que, de alguma forma, os inclui naquela escola, naquela relação professor-aluno, indicando inclusive o mal-estar do próprio professor. Embora saibamos que o relatório se constitui em um texto bastante resumido e específico, centrado prioritariamente no aluno, ele também se mostrou material rico, trazendo marcas e nuances do mal-estar dos professores de nosso tempo.

\section{CONSIDERAÇÕES FINAIS}

Ainda que o uso de fóruns e publicações online sobre relatório escolar esteja bastante difundido no contemporâneo, parece-nos que há uma espécie de escassez na produção mais crítica sobre o assunto. As dicas que direcionam o uso e a forma do relatório, servindo de amparo para este tipo de intervenção docente, predominantemente dizem como fazer, mas não questionam o fazer em si, para qual finalidade e a quê podem estar a serviço.

O mal-estar, proposto por Freud em meados do século $\mathrm{XX}$, perpassa as relações sociais hoje, mesmo que de formas diferentes. A partir dos relatórios, na escrita dos educadores, encontramos, predominantemente, referências ao mal-estar gerado por um aluno que não corresponde ao lugar de aluno que construímos como ideal, aceito, esperado. Nesse ponto, é importante ressaltar que esta forma de mal-estar atravessou os diferentes materiais produzidos na pesquisa, não somente a partir do discurso da escola, mas também no discurso médico e familiar. O que podemos observar de particular dentro do campo educacional, é que o ideário de aluno atravessa toda relação professor-aluno, mas pouquíssimas vezes ele é problematizado. Há uma espécie de silenciamento sobre a dimensão idealizante que envolve a relação professor aluno e que, muitas vezes, atravessa o sistema escolar de forma mais ampla, acarretando como consequência uma segregação daqueles que não correspondem ao idealizado. Nesse sentido, levantamos a hipótese de que o relatório escolar, além de ser utilizado como uma ferramenta descritiva do cotidiano do aluno, também pode servir como rico material para pesquisa do mal-estar de professores, já que pode oferecer marcas dos ideais que atravessam o fazer docente e suas frustrações. Desta forma, pode ser pensado como estratégia de intercâmbio da escola que, além da troca de informações, divide sua tensão com outras instâncias que também constituem o processo educacional, seja a família ou um especialista do campo da saúde. Percebe-se também com essa prática a dificuldade que a organização escolar encontra de criar dispositivos internos para refletir e problematizar seu modelo ideal de aluno, em contraposição ao corpo discente presente.

\section{REFERÊNCIAS}

Aguiar, R. M. R., \& Almeida, S. F. C. D. (2006). Professores sob pressão: sofrimento e mal-estar na educação. Proceedings of the 6th Psicanálise, Educação e Transmissão.

Aguiar, R. M. R., \& Almeida, S. F. C. D. (2008). Mal-estar na educação: 0 sofrimento psíquico de professores. Juruá.

Aquino, J. G. (2005). Jovens "indisciplinados" na escola: quem são? Como agem. Simpósio Internacional do adolescente, 1.

Aquino, J. G. (2011). Da (contra) normatividade do cotidiano escolar: problematizando discursos sobre a indisciplina discente. Cadernos de pesquisa, 41 (143), 456-484. https://doi.org/10.1590/S010015742011000200007

Bizarro, R., \& Braga, F. (2005). Ser professor em época de mal-estar docente: que papel para a universidade. $R e-$ vista da Faculdade de Letras: Línguas e Literaturas, II série, vol. 22 , 17-27.

Carneiro, C., \& Coutinho, L. G. (2015). Infância e adolescência: como chegam as queixas escolares à saúde mental? Educar em Revista, 56, 181-192. https://doi. org/10.1590/0104-4060.37764

Carneiro, C., de Souza, L. T. R., Coutinho, L. G., \& da Silva, R. D. P. F. (2016). Adolescência e expressões do mal-estar na escola: estudo de casos. Estilos da Clínica, 21(3), 548-572. https://doi.org/10.11606/issn.19811624.v21i3p548-572

Correa, C. (2010). Ideal e autoridade na educação. Arquivos Brasileiros de Psicologia, 62(1), 02-12.

Cortez, P. A., Souza, M.V.R., Amaral, L. O. \& Silva, L. C. A. D. (2017). A saúde docente no trabalho: apontamentos a partir da literatura recente. Cadernos Saúde Coletiva, 25 (1), 113-122. https://doi.org/10.1590/ $1414-462 \times 201700010001$ 


\section{W NTERAC̄̃oEM PSICOLOGIA}

Diniz, M. (1998). De que sofrem as mulheres-professoras? In: Lopes, E. M. T. (Org.) (1998). A psicanálise escuta a educação (pp. 198-223). Autêntica.

Esteve, J. M. (1999). O mal-estar docente: a-sala-de-aula e a saúde dos professores. EDUSC.

Ferreira, M. B. C., \& Pereira, M. R. (2012). O mal-estar docente na educação infantil. An $9 \mathrm{Col}$. LEPSI/FE-USP.

Freitas, L. G., \& Facas, E. P. (2013). Vivências de prazer-sofrimento no contexto de trabalho dos professores. Estudos e Pesquisas em Psicologia, 13 (1), 7-26. https:// doi.org/10.12957/epp.2013.7880

Freud, S. (1988). Análise terminável e interminável. In: Edição Standard Brasileira das Obras Psicológicas Completas (J. Salomão, trad., Vol. 23, pp. 225-231). Imago. (Originalmente publicado em 1937).

Freud, S. (1995). O Mal-estar na Civilização. In: Obras Completas de Sigmund Freud (2.ed.). Imago. (Originalmente publicado em 1930).

Gama, Z. (2006). Avaliação nos Ciclos de Formação: mudanças e novas direções nas escolas municipais do Rio de Janeiro. Estudos em Avaliação Educacional (Online), v. 17, p. 105. https://doi.org/10.18222/ eae173320062129

Kupfer, M. C. M. (2001). Freud e a educação: o mestre do impossível. São Paulo: Scipione

Lajonquière, L. (1997). Dos "erros" e em especial daquele de renunciar à educação: Notas sobre psicanálise e educação. Estilos da Clínica, 2 (2), 27-43. https://doi. org/10.11606/issn.1981-1624.v2i2p27-43

Lebrun, J.-P. (2010). A perversão comum: viver juntos sem outro. Companhia de Freud.

Pereira, M. R. (2003) O avesso do modelo: bons professores e a psicanálise. Vozes.

Pereira, A. \& Blum, V. (2014). Poder, resistência e indisciplina escolar: a perspectiva docente sobre os comportamentos transgressores dos alunos. Revista de Educação Pública, 23(54), 739-757. https://doi. org/10.29286/rep.v23i54.1273

Pizzio, A., \& Klein, K. (2015). Qualidade de vida no trabalho e adoecimento no cotidiano de docentes do Ensino Superior. Educação \& Sociedade, 36 (131). https://doi. org/10.1590/ES0101-73302015124201
Ratto, A. (2007) Livros de ocorrência:(in)disciplina, normalização e subjetivação. Cortez.

Resolução SME n 1123/2011. (2011) Estabelece diretrizes para a avaliação escolar na Rede Pública do Sistema Municipal de Ensino da Cidade do Rio de Janeiro e dá outras providências. Secretaria Municipal de Educação. portais.rioeduca.rio.gov.br/Portais/4/Arquivos/08-RESOLUÇÃO_1123.doc

Sanches, A. P. R. \& Gama, R. P. (2016). O mal-estar docente no contexto escolar: um olhar para a produção acadêmica brasileira. Laplage em Revista, 2(3), 149-162. https://doi.org/10.24115/S24466220201623188p.149-162

Silva, E. M. A. (2012). Mal-estar: marca da escola na contemporaneidade? Retratos do mal-estar contemporâneo na educação: Anais do 9o Colóquio LEPSI IP/ FE-USP.

Siqueira, M. J. T. \& Ferreira, S. E. (2003). Saúde das professoras das séries recentes: o que o gênero tem a ver com isso ?. Psicologia: Ciência e Profissão, 23 (3), 76-83. https://dx.doi.org/10.1590/S141498932003000300011

Vieira, S. R. S. (2014). Sofrimento psíquico e trabalho. Revista Latinoamericana de Psicopatologia Fundamental, 17(1), 114-24. http://dx.doi.org/10.1590/S141547142014000100009.

Vieira, J. S., Gonçalves, V. B, \& Martins, M. F. D. (2016). Trabalho docente e saúde das professoras de educação infantil de Pelotas, Rio Grande do Sul. Trab. Educ. Saúde,14(2), 559-74. https://doi.org/10.1590/ 1981-7746-sip00119

Zibetti, M. (2004). A angústia no ofício de professor: angústia docente. Psicologia Escolar e Educacional, 2(8), 219-225. https://doi.org/10.1590/S141385572004000200010

Data de submissão: 04/09/2019 Primeira Decisão Editorial: 16/02/2020 Aceite em 19/03/2020 